\title{
CRITERIOS A CONSIDERAR PARA UNA REFORMA DEL SISTEMA TRIBUTARIO CHILENO*
}

\author{
José Pablo Arellano \\ Cieplan \\ Vittorio Corbo \\ CEP
}

\begin{abstract}
En este documento se reproduce el primer capítulo del libro Tributación para el desarrollo (2013), que contiene los resultados del análisis del sistema tributario chileno y de las oportunidades de mejora, realizado conjuntamente por el CEP y Cieplan. Basados en la teoría y evidencia de las finanzas públicas, en el estudio de las reformas tributarias introducidas y propuestas en países de la OCDE y la experiencia nacional e internacional, este artículo contiene una propuesta de reformas orientadas a mejorar el funcionamiento del sistema tributario chileno y, al mismo tiempo, obtener recursos
\end{abstract}

José Pablo Arellano. Investigador senior de la Corporación de Estudios para Latinoamérica (Cieplan).

Vittorio Corbo. Investigador asociado senior del Centro de Estudios Públicos (CEP).

* Capítulo 1 del libro Tributación para el desarrollo: Estudios para la reforma del sistema chileno, editado por José Pablo Arellano y Vittorio Corbo (Santiago: CEP/Cieplan, 2013). La última revisión del capítulo fue realizada el 10 de mayo de 2012, por tanto cambios posteriores en la legislación tributaria no son considerados. 
adicionales para financiar el presupuesto público sustentablemente. La propuesta incluye la eliminación de distorsiones que el esquema tributario introduce, ganancias de eficiencia en el cumplimiento tributario y la administración del sistema, mejoras a la equidad horizontal y a la progresividad del sistema a través de la eliminación de una serie de regímenes especiales y una un ajuste en impuestos específicos para proteger el medio ambiente, sin afectar los incentivos al ahorro, la inversión y el crecimiento.

Contenido:

1. Principios generales de un sistema tributario eficiente y equitativo

2. El sistema tributario actual en Chile: Aspectos destacados

3. Recomendaciones de reforma 216

$\mathrm{E}_{1}$ desarrollo y la democracia en una sociedad moderna requieren de un Estado capaz de proveer un nivel de bienes públicos compatible con el nivel de ingreso per cápita del país y financiados en forma sostenible por un buen sistema tributario. Un buen sistema tributario debe recaudar un nivel de recursos predeterminado en forma equitativa y lo debe hacer minimizando los costos de eficiencia, de administración y de cumplimiento. En Chile, con el aumento del ingreso promedio de las familias, ha surgido la necesidad de aumentar el nivel de gasto público permanente para que, unido con una mayor eficiencia en su uso, se pueda avanzar con más fuerza en mejorar la oferta de bienes públicos.

Son estas ideas centrales las que llevaron a CEP y a CIEPLAN a proponerse un examen del sistema tributario chileno, con miras a sugerir cambios en este que contribuyan a mejorar la equidad, la eficiencia y la progresividad del esquema y, al mismo tiempo, a movilizar, de la mejor forma posible, recursos adicionales para el sector público. Cuando se planteó esta iniciativa, hace alrededor de dos años, el tema no estaba en la agenda nacional. Hoy en cambio se ha convertido en un tema cotidiano y seguramente será materia de debate durante varios meses. 
Para llevar a cabo este proyecto se constituyó un grupo de trabajo y se asignaron responsabilidades específicas a tres especialistas para examinar el sistema tributario chileno. El grupo encargado de emprender esta tarea estuvo compuesto por los dos codirectores del proyecto, José Pablo Arellano y Vittorio Corbo, en conjunto con Claudio Agostini — encargado del estudio de impuestos a la renta—, José Yáñez —encargado del estudio de los impuestos indirectos_- Michel Jorratt —encargado del estudio de evaluación del gasto tributario y de políticas para reducir la evasión - y Jorge Rodríguez Cabello y Ricardo González, que colaboraron con el equipo de trabajo. En las primeras etapas del proyecto también cooperó Jorge Desormeaux Matthei. Los progresos en la elaboración de los trabajos se analizaron en reuniones semanales de trabajo. Asimismo, se realizaron varias sesiones de trabajo con especialistas en el tema y con personas que han sido responsables de la administración y política tributaria en distintos momentos de nuestra historia. El fin último de este proyecto es aportar antecedentes para definir los cambios más convenientes para nuestro sistema tributario, a partir de un diagnóstico de su realidad actual. Para ese efecto, en este proyecto se han revisado las recomendaciones de la teoría de finanzas públicas, la evidencia empírica de la literatura económica nacional e internacional, las recomendaciones de reformas tributarias hechas en Chile y en el extranjero, especialmente los proyectos de reforma tributaria más relevantes de los últimos años en los países de la OCDE.

En este capítulo se ofrece una síntesis de las conclusiones del proyecto con propuestas de reforma basadas en los trabajos que han formado parte de este proyecto y en la discusión generada en torno a ellos. Se inicia este capítulo con una revisión de los principios generales que deben servir de base a un sistema tributario eficiente y equitativo. Luego se repasan las características principales del sistema chileno, para concluir con recomendaciones para mejorar su eficiencia, su progresividad y su equidad.

\section{Principios generales de un sistema tributario eficiente y equitativo}

En una sociedad moderna el sector público juega un rol central para proveer bienes públicos necesarios para el funcionamiento adecuado de la sociedad. En particular, la justicia, la seguridad, la institucionalidad 
financiera, el marco regulatorio de los mercados, el cumplimiento de los contratos, la defensa, la ley y el orden, el acceso de los más pobres a servicios básicos, y la institucionalidad pública son fundamentales para el buen funcionamiento de una democracia y de una economía de mercado. Dado el nivel de gasto público elegido por una sociedad, es necesario ejecutarlo en forma eficiente y financiarlo de la forma más equitativa y eficiente posible. Esto es, un sistema tributario que recaude un nivel de impuestos que permita financiar el nivel de gasto público elegido, de acuerdo a su institucionalidad, generando las menores distorsiones posibles en la toma de decisiones de los agentes económicos, y que satisfaga los principios centrales de equidad horizontal y de progresividad que debe cumplir todo sistema tributario. Debe entenderse eso sí que las transferencias del Estado son un complemento central al sistema tributario. Por lo tanto, la progresividad debe ser analizada en forma conjunta, considerando el esquema tributario y de transferencias del Estado ${ }^{1}$.

La estructura tributaria afecta la conducta de personas y empresas, pudiendo generar costos importantes que hay que tomar en cuenta al evaluar dicho esquema. En particular, los impuestos influyen sobre las decisiones de los agentes económicos, afectando el tiempo dedicado al trabajo y al ocio, el ahorro y la inversión y por esa vía influyen sobre la eficiencia en el uso de los recursos, el crecimiento y el bienestar de la población. Además, su implementación implica costos administrativos para el gobierno, tanto en la recaudación como en la fiscalización del cumplimiento del sistema. También los contribuyentes incurren en costos para cumplir con sus obligaciones tributarias. En sistemas tributarios complejos y con muchas exenciones y regímenes especiales, los contribuyentes también invierten en actividades poco productivas para la sociedad con el fin de eludir el pago de sus obligaciones tributarias sin salirse del ámbito legal. Por lo tanto, en su diseño hay que considerar no solo la recaudación que se obtiene, sino que también los comportamientos y conductas que induce y los costos de operar el sistema y de cumplimiento para el Estado y para los contribuyentes.

Para un nivel dado de gasto público a financiar y para objetivos distributivos predefinidos, un sistema tributario eficiente y equitativo es uno que procura minimizar las distorsiones, busca asegurar la

1 En la literatura económica se define un impuesto como progresivo si la tasa media del impuesto aumenta con el ingreso. No obstante, evaluar la progresividad de la política fiscal de manera integral implicaría mirar tanto la progresividad del sistema tributario como la del gasto público. Nótese que eso no cambia la definición de progresividad de un impuesto en particular. 
equidad horizontal, junto con el sistema de subsidios, monetarios y no monetarios; promueve la progresividad, y al mismo tiempo minimiza los costos de administrar el sistema tanto para el Estado como para los contribuyentes.

Los principios básicos de un sistema tributario eficiente y equitativo fueron analizados recientemente, en detalle, por la comisión presidida por el premio Nobel de Economía, James Mirrlees, quien por encargo del Instituto de Estudios Fiscales del Reino Unido, un ente autónomo de gran prestigio, reunió a destacados economistas y policymakers con el objetivo de hacer propuestas para mejorar el sistema tributario del Reino Unido, de modo que el gobierno obtuviera el ingreso fiscal y los objetivos redistributivos deseados de forma más eficiente que con la estructura vigente ${ }^{2}$. Para ello, dicha comisión estableció que una estructura tributaria eficiente debiera ser simple, transparente y coherente con la evidencia teórica y empírica sobre los efectos de los impuestos en las decisiones de personas y empresas, de modo de recaudar el nivel deseado de ingresos al menor costo posible. La simpleza del sistema ayudaría a reducir los costos de administración y cumplimiento de la estructura tributaria, al tiempo que la evidencia teórica y empírica ayudaría a determinar la forma en que la base tributaria debiera ser definida para minimizar sus costos de eficiencia y la progresividad que debiese tener el sistema para cumplir con los objetivos distributivos en forma eficiente.

Del estudio anterior y de una amplia literatura económica sobre el tema, se derivan una serie de principios que debiera cumplir una estructura tributaria eficiente:

(i) En general un sistema tributario óptimo debe incluir una combinación de impuestos al ingreso e impuestos al consumo

En un esquema ideal, la base del impuesto debiera ser la capacidad de cada persona de generar ingresos a lo largo de toda su vida. Pero como esto no es observable en forma directa, se hace necesario utilizar

${ }^{2}$ El informe de Mirrlees et al. (2011) tuvo un ámbito más amplio que el abarcado por el informe del Comité presidido por otro premio Nobel, James Meade, en 1978, que se limitó a proponer reformas a la tributación directa. Dicho informe también ha sido un clásico en la teoría y la práctica de las reformas tributarias. Véase Meade (1978). 
medidas indirectas de esta capacidad. Esto se logra en forma óptima combinando un impuesto a los ingresos con un impuesto al gasto. El impuesto al gasto o consumo tiene la ventaja de que no desincentiva el ahorro y el trabajo y, al estar el consumo más correlacionado con el ingreso permanente, toma en cuenta el ingreso más permanente de los contribuyentes.

\section{(ii) Como regla general hay que evitar discriminar entre actividades}

Un sistema tributario eficiente debiera fijar la misma tasa impositiva para todas las actividades que sean similares, para así evitar distorsiones. En efecto, cuando el tratamiento es muy disímil, las actividades menos favorecidas tienden a "disfrazarse" de aquellas que gozan de algún beneficio tributario. Además, una estructura pareja contribuye a reducir los costos de cumplimiento porque simplifica el monitoreo de dichas actividades. En particular, en lo que al IVA se refiere, dicho impuesto debiera ser de tasa pareja y aplicarse a todas las actividades que generan valor agregado. En casos de actividades en las que la aplicación del IVA pueda resultar muy costosa (por ejemplo, aquellas en que es más difícil definir el valor agregado), se recomienda utilizar impuestos que se asemejen a un IVA. Este puede ser el caso del impuesto de timbres y estampillas en el sector financiero.

La excepción a esta regla son algunas actividades o bienes que, por su naturaleza, es eficiente que reciban un tratamiento tributario diferente. Es el caso del consumo de cigarrillos y alcoholes y de las actividades que dañan el medio ambiente. Dichas actividades producen externalidades negativas que implican un costo para el resto de la sociedad, lo que hace necesario desincentivarlas imponiéndoles un impuesto equivalente a la externalidad negativa que generan. Un buen instrumento para hacerlo son los impuestos que encarezcan el consumo de esos bienes y/o la producción de esas actividades según la externalidad que se genere en el consumo o en la producción. En particular, en este sentido cobran cada día más importancia, y lo seguirán haciendo en el futuro, los llamados impuestos verdes que buscan encarecer el uso de productos que son ambientalmente perjudiciales.

Por el contrario, hay actividades que producen beneficios para la sociedad más allá de los beneficios privados y que debieran incentivarse a través de subsidios explícitos o rebajas impositivas. En esta categoría, 
se encuentra el ahorro previsional, las contribuciones a planes de salud $\mathrm{y}$ algunas otras actividades en las que el beneficio social de su consumo o ejecución es mayor que su beneficio privado (por ejemplo, investigación y desarrollo, las artes y la cultura).

Sin embargo, es preciso ser muy cuidadosos con las excepciones, porque ellas aumentan los costos de cumplimiento del sistema y crean incentivos para que las actividades que no cumplen los principios de la excepción se hagan pasar por ese tipo de actividades para capturar dicho beneficio. Así, una estructura pareja y simple, esto es, sin regímenes especiales, reduce los incentivos de evasión, planificación y elusión tributaria (los incentivos tributarios alteran en forma importante las decisiones de empresas y personas). Es por eso que el número de actividades que recibe un tratamiento tributario diferencial debe reducirse al mínimo.

Esta neutralidad del sistema tributario, también debe alcanzar a territorios y regiones, particularmente en un país políticamente unitario como Chile. El sistema tributario no es el mejor mecanismo para estimular la localización de empresas o compensar por diferencias en el costo de vida en distintos lugares.

\section{(iii) En cuanto a los impuestos a la renta}

Se debe velar por la equidad horizontal y vertical. Respecto a la equidad horizontal, dos personas con el mismo ingreso debieran pagar el mismo monto de impuestos independientemente de las fuentes de ingreso. En cuanto a la equidad vertical, personas con mayores ingresos, independiente de su fuente, deben pagar mayores impuestos.

Para darle un carácter progresivo al impuesto a la renta, las personas con más ingresos deben pagar una mayor proporción de su ingreso en impuestos, pero el sistema tributario no debe alterar el ranking de ingresos de las personas antes y después de impuestos. Para que un sistema tributario sea adecuadamente progresivo, este debe reflejar la evidencia más precisa sobre la distribución del ingreso del país y los efectos que el sistema tributario tiene sobre el comportamiento de las personas en distintos niveles de ingreso.

En aras de la simpleza, para evitar distorsiones y para lograr una cierta progresividad, todas las fuentes de ingreso (ingreso de trabajadores dependientes e independientes, ingresos por arriendos de propieda- 
des, ahorros, rentas empresariales, dividendos y ganancias de capital) deberían enfrentar la misma estructura tributaria. De lo contrario, surge una serie de distorsiones que afecta las decisiones económicas, que buscan la apropiación de rentas y que, en último término, constituyen el motivo de evasión tributaria, terminan generando inequidades y le restan progresividad al impuesto a la renta.

Para que todas las fuentes de ingreso estén afectas a la misma estructura tributaria es fundamental que el sistema esté completamente integrado, es decir, que las rentas que se perciben como empleado dependiente, como dueño o accionista de empresa y como empleado independiente, estén reunidas en un solo sistema y que, entonces, se apliquen las tasas impositivas correspondientes. De esta manera, se reducen los costos de administración del sistema y se logra la equidad horizontal.

Se podría pensar que si todas las fuentes de ingreso enfrentan la misma estructura tributaria, entonces no sería necesario imponer una tasa de impuesto a las empresas por cuanto las ganancias derivadas de ellas se pueden incorporar en la categoría correspondiente del impuesto a la renta. Sin embargo, es imprescindible introducir un impuesto corporativo a las empresas, con un crédito en el impuesto a las personas, porque es conveniente para la administración del sistema y para reducir la evasión. De lo contrario, el sistema debería determinar el porcentaje de propiedad de cada uno de los propietarios de todas las empresas de la economía, lo que sería excesivamente costoso, aun con la tecnología moderna. Así, en un sistema eficiente, las empresas actúan también como recaudadoras del impuesto, reduciendo los costos administrativos del sistema como un todo. La experiencia internacional también muestra que los impuestos que tienen retención en la fuente disminuyen fuertemente la evasión y la elusión.

En un sistema como el chileno lo anterior se logra mediante el impuesto a las empresas, que es un crédito en el global complementario de las personas. En esto, el sistema tributario chileno se encuentra en la frontera de los sistemas tributarios de los países de la OCDE. De hecho, las últimas tres propuestas de reformas tributarias hechas por comisiones de expertos en EE.UU. también han incluido esta propuesta.

Además, la base imponible del impuesto a las empresas debe descontar todos los costos necesarios para generar ese ingreso. De lo contrario, surgen distorsiones que favorecen a las actividades de bajos 
costos que generan pocos ingresos en desmedro de actividades de altos costos que generan altos ingresos. De la misma manera, debiera descontarse de la base la inversión en capital, porque esta es un insumo de los ingresos que se generarán en el futuro, los que serán gravados en el momento en que se generen.

Asimismo, en el impuesto a la renta de las personas, el ahorro debiera considerarse como un insumo para aumentar el ingreso y el consumo futuro. Por lo tanto, el retorno normal del ahorro debería estar exento de impuesto. De esta forma, se acercaría más a un sistema de un impuesto progresivo al gasto. El exceso de retorno sí debiera estar afecto a impuesto, porque este componente es pura renta económica y, como tal, no se crean distorsiones cuando se les obliga a los contribuyentes a pagar por esas rentas. Por consiguiente, el impuesto sobre este exceso no desincentiva el ahorro. Las tasas que se deberían aplicar por dichas rentas serían simplemente las que correspondan de acuerdo al tramo del ingreso personal que alcancen, incluyendo esas rentas, y no enfrentar una tasa especial. Respecto al riesgo, incluido en el retorno del ahorro, este debiera ser compartido por el Estado con un sistema de crédito por pérdidas que puedan llevarse hacia delante y hacia atrás en el sistema tributario.

Por otra parte, la base del impuesto debiera ser lo más amplia posible, con pocas exenciones, y así recaudar un monto determinado de ingresos tributarios con tasas más bajas y reducir efectos no deseados (en contraposición a los impuestos específicos) en la asignación de recursos. A su vez, la reducción de exenciones hace al impuesto a la renta más eficiente, más justo, además de que disminuye la elusión, la evasión y los costos de administración y cumplimiento.

(iv) Los regímenes especiales y exenciones al impuesto a la renta terminan rompiendo la equidad horizontal, generan ineficiencias y promueven la elusión y la evasión. Adicionalmente, terminan también reduciendo la progresividad del sistema

En particular, la tasa del impuesto a las empresas debe ser única. Las diferencias por tamaño de empresas o por sector económico incentivan la evasión y la elusión, y terminan generando inequidades e ineficiencias y también reducen la progresividad del impuesto a la renta. Así, no es una buena política pretender favorecer a las medianas 
y/o pequeñas empresas con un trato tributario especial. Ello originará situaciones de inequidad y facilitará la elusión, por cuanto las empresas tendrán incentivos para dividirse y así evitar o reducir el pago de su obligación tributaria. En el caso de las empresas más pequeñas, para reducir sus costos de cumplimiento, se propone más abajo un esquema simplificado, que aprovecha los actuales sistemas tecnológicos para simplificar al máximo el cumplimiento tributario.

Donde sí se justifica un trato diferente es en el caso de los recursos naturales que generan rentas. Excepcionalmente en ese caso se justifica un gravamen específico sobre esa renta. De acuerdo a las recomendaciones de la teoría económica, la base de este impuesto debe ser las utilidades operacionales o el flujo de caja, no la cantidad del recurso extraído ${ }^{3}$.

(v) La progresividad de las finanzas públicas hay que analizarla considerando el sistema tributario, las transferencias y los subsidios del Estado como un todo y no tomando cada componente por separado (impuesto a la renta de las personas, impuesto a la renta de las empresas, IVA y subsidios públicos)

Para lograr progresividad en la política fiscal se debe analizar en forma conjunta la totalidad del sistema tributario, las transferencias y los subsidios del Estado.

La mejor forma de redistribuir es utilizando una combinación de impuestos progresivos al ingreso con un sistema de subsidios focalizados en los grupos de más bajos ingresos. De esta manera, el resto de los impuestos (por ejemplo, el IVA, impuesto a los combustibles y al tabaco, y cobro por uso de servicios) no debieran fijarse con objetivos redistributivos, sino que debieran estar enfocados en lograr una adecuada recaudación y también contribuir a lograr una mayor eficiencia en el uso de los recursos que gravan el consumo y no la inversión. Para esto último, el IVA es un impuesto eficiente, de acuerdo a lo que se expone más abajo.

En particular, el IVA es un impuesto al consumo que minimiza distorsiones, porque se aplica a todas las actividades que generan valor agregado, y por lo tanto, es un impuesto eficiente. Así, no deberían

${ }^{3}$ Véase Agostini (2012). 
existir impuestos con un uso específico predefinido de los ingresos recaudados (no earmarking). Al IVA no se le deben pedir objetivos distributivos sino de recaudación. Para el logro de objetivos distributivos, se debe utilizar el impuesto a la renta, combinado con subsidios y transferencias a las personas o familias necesitadas.

\section{(vi) El sistema tributario debe ser suficiente, estable, competitivo y unificado}

El sistema tributario debe ser suficiente para financiar el gasto fiscal, ajustado por el ciclo de manera sustentable, esto es, manteniendo la solvencia del Estado y velando por el bienestar de las generaciones futuras. En una economía como la chilena, en la que los ingresos del cobre son muy relevantes para el fisco y, dadas las grandes fluctuaciones de los precios de este metal, este aspecto es especialmente relevante. En este sentido, el manejo fiscal en base a los ingresos estructurales ajustados por el ciclo, que el país viene aplicando por más de veinte años — que se perfeccionó en la década pasada con la introducción de una regla de balance fiscal ajustado por el ciclo de precios del cobre y del PIB-, es un criterio esencial que debe preservarse. Los ingresos tributarios estructurales o ajustados por el ciclo deben ser suficientes en el mediano plazo y deben evaluarse más allá de la coyuntura. Es mérito, en parte, de la política fiscal y, como parte de ella, de la estructura tributaria, que el país esté próximo a cumplir treinta años sin una crisis fiscal, habiendo ocurrido dos crisis internacionales severas en ese lapso de tiempo. Esto representa un quiebre con nuestra historia económica anterior. Otros dos factores que han contribuido a la estabilidad macroeconómica del país son la política monetaria conducida por un Banco Central autónomo, con un mandato explícito de velar por la estabilidad de precios, y una apropiada regulación y supervisión bancaria.

El sistema tributario debe ser estable para dar un horizonte de planificación adecuado a las personas y empresas y de esa forma contribuir a reducir la incertidumbre. Ello requiere que los cambios a la legislación tributaria se hagan con la debida preparación y consenso político para lograr su estabilidad en el tiempo.

El sistema tributario debe ser competitivo para que el país pueda competir en un mundo globalizado, en el que personas y empresas toman decisiones de consumo, inversión y localización, teniendo en cuenta la situación tributaria de los países y territorios en que pueden operar. 
Esto es especialmente relevante en economías pequeñas y abiertas a los flujos comerciales, financieros y de inversión extranjera directa como es Chile.

El sistema tributario debe ser unificado, evitando la afectación de impuestos y la fragmentación de su recaudación. En un país unitario y pequeño como Chile debe evitarse la fragmentación de la recaudación por niveles de gobierno o por áreas geográficas, así como la afectación de los impuestos. La afectación de los ingresos, una vez que se admite en un caso, termina inevitablemente extendiéndose a otros impuestos. Ello rigidiza la política fiscal e impide lograr eficiencia y equidad de la recaudación a medida que cambian las condiciones. La experiencia histórica internacional en materia fiscal muestra que la fragmentación y afectación tributaria con frecuencia son causas de crisis fiscales y de ineficiencia tributaria.

A la luz de estos principios y de las mejores prácticas internacionales, este proyecto ha examinado la situación actual del sistema tributario chileno y se hacen recomendaciones de reforma. Para definir las mejores prácticas conviene examinar no solo la situación actual de los países que destacan por sus sistemas tributarios y su realidad fiscal, sino especialmente las tendencias de cambio observadas en la última década, así como las orientaciones de las propuestas de reforma más recientes. Aparte de la propuesta de reforma de la comisión, encabezada por Mirrlees ya mencionada ${ }^{4}$, se analizaron también las propuestas de reforma en EE.UU. ${ }^{5}$ y el recuento de tendencias de reforma en la OCDE ${ }^{6}$.

\section{El sistema tributario actual en Chile. Aspectos destacados}

El sistema tributario chileno, comparado al de los países de la OCDE, tiene una serie de elementos que se consideran como constitutivos de los buenos sistemas tributarios. De hecho, varias de las propuestas recientes de reforma en esos países pretenden introducir aspectos que ya están resueltos en Chile.

Neutralidad. El sistema tributario chileno está totalmente indexado a la inflación. La indexación del sistema tributario comenzó a

${ }^{4}$ Véase Mirrlees et al. (2011).

5 Véase Report of the President's Advisory Panel on Federal Tax Reform (2005).

${ }^{6}$ Véase Brys et al. (2011). 
introducirse por ley en los años sesenta y se completó en 1975. Ello nos permite contar con una legislación tributaria neutral frente a la inflación y que consigue estabilidad en el tiempo. Además, existe integración de impuestos a personas y empresas, que tal como se discutió en la sección anterior se considera como uno de los elementos que debiera incorporar un sistema tributario eficiente. El IVA y los demás impuestos tienen en general tasas parejas, lo cual contribuye a la neutralidad, aunque hay excepciones que requieren evaluarse.

Existe una cultura de cumplimiento relativamente alta, simplicidad e incorporación de nuevas tecnologías. La cultura de cumplimiento y el combate a la evasión no solo son importantes desde el punto de vista tributario, sino que simultáneamente persiguen las actividades ilícitas en general: drogas y crimen. Esta cultura de cumplimiento es un activo del país que se debe preservar y fortalecer. El uso de tecnologías está bastante difundido en el país, al punto que casi el 100\% de las declaraciones de global complementario se hacen en línea. Asimismo, está extendido el uso de boletas electrónicas y se ha estado avanzando en el uso de la factura electrónica.

Estructura tributaria concentrada en impuestos al consumo. Existe mayor énfasis en impuestos indirectos que gravan el consumo, especialmente a través del IVA. Con ello se reducen los desincentivos al trabajo, al ahorro y a la inversión. Es precisamente por esta razón que en los países de la OCDE la tendencia de los últimos veinte años ha sido elevar la importancia de este impuesto ${ }^{7}$. Chile se ubica entre los cinco países de la OCDE de mayor importancia del IVA como proporción del PIB (después de Noruega y Suecia) ${ }^{8}$.

El sistema chileno es unificado y sin afectaciones, aunque hay excepciones. Una es la ley reservada del cobre que debería terminarse y sobre la cual existe un proyecto de ley que se está discutiendo en el Congreso. Otras son las contribuciones a los bienes raíces, en cuyo caso una fracción del monto recaudado es asignado a la municipalidad correspondiente, y el royalty a la minería, en el que una fracción de la recaudación se asigna a la región donde se extraen los recursos.

${ }^{7}$ Véase Brys et al. (2011).

${ }^{8}$ Es importante destacar que tanto Noruega como Suecia tienen una muy buena distribución del ingreso, resultado al que contribuyen la progresividad del impuesto a la renta y las transferencias del Estado. 
A pesar de sus claras fortalezas, el sistema tributario chileno tiene espacio para mejoras, especialmente si se reducen exenciones y franquicias que muchas veces terminan promoviendo la elusión y la evasión y afectan la equidad horizontal y la progresividad del impuesto a la renta. Como se detalla más adelante en el trabajo de Jorratt, desde 2001 se lleva un registro del costo de las franquicias o exenciones, el llamado gasto tributario, en el que se puede apreciar cómo estas han aumentado en cantidad. Además, en lo que se refiere a impuestos indirectos específicos, hay oportunidades para mejorar la eficiencia en el uso de recursos y contribuir al medio ambiente mediante reformas de los impuestos a los combustibles.

\section{Recomendaciones de reformas}

\section{(i) Evasión}

La reducción de la evasión debería ser primera prioridad. Con ello se contribuye a aumentar la eficiencia y equidad horizontal, condicional al esquema tributario existente. De acuerdo a los antecedentes sobre evasión del IVA del SII, la evasión llegó a un mínimo del 8\% de los ingresos tributarios potenciales el año 2007 para subir después a un $12 \%$ el año 2008 y a un $18 \%$ el 2009. En el trabajo de Jorratt se estima que esta tasa se habría reducido al $16 \%$ el 2010 y al 14\% el 2011. La subida del 2008-2009 coincide con la Gran Crisis Financiera internacional, que tuvo un impacto negativo importante en la economía chilena. Reducir la evasión del IVA desde el 14\% actual al promedio alcanzado los dos años anteriores a la crisis, cuando llegó a un 8,5\%, permitiría recaudar unos US\$ 1.100 millones anuales. En el caso del impuesto de primera categoría, reducir la tasa de evasión a los niveles alcanzados para el promedio anual 2006-2007, permitiría recaudar algo más de US\$ 800 millones anuales 9 .

Para ello, en el trabajo de Jorratt a continuación, se sugiere una serie de medidas administrativas que en poco tiempo debieran permitir, al menos, hacer retroceder la evasión a los niveles previos a la crisis. Estas medidas requieren fortalecer la capacidad de recaudación del SII

${ }^{9}$ Esta estimación se refiere solo a la recaudación del impuesto de primera categoría, no incluye la posible recaudación adicional sobre el global complementario. La cifra se basa en las tasas de tributación vigentes en 2011. 
a fin de mejorar la fiscalización a base de tecnologías de información, orientándola en función del riesgo de evasión (por ejemplo, incorporando las experiencias internacionales respecto al tema), y seguir extendiendo el uso de documentación electrónica en el cumplimiento tributario, en particular, promoviendo el uso generalizado de las facturas electrónicas, ya que la principal fuente de evasión del IVA sería el uso de facturas falsas. Para ello, es necesario elevar las capacidades del SII en fiscalización y acceso a información, mejorar la medición de precios de transferencia (utilizando las normas de la OCDE sobre esa materia), e incorporar normas antielusión en el Código Tributario. Esto último es necesario para reducir los incentivos a utilizar planificación tributaria con el objetivo último de evitar el pago de impuestos. El SII debería dar señales claras de una mayor prioridad al combate a la evasión y difundir sus acciones orientadas a este fin, lo cual históricamente ha probado ser efectivo para lograr una mejor práctica de cumplimiento. Asimismo, es conveniente reforzar el combate a la evasión ampliando la información que entrega regularmente el SII sobre sus resultados en esta materia.

\section{(ii) Eliminación de franquicias, exenciones y regímenes especiales}

Como ya se ha señalado, las franquicias y las exenciones y/o regímenes especiales deben limitarse a situaciones muy excepcionales, ya que generan inequidades horizontales, son fuente de ineficiencias y facilitan la evasión y elusión. Por ese motivo, a continuación, se enumeran una serie de esas normas que después de examinarlas resulta conveniente eliminar o revisar a fondo. Como criterio general, debe evitarse la creación de nuevas franquicias o regímenes especiales, y los que se han creado, deben evaluarse cuidadosamente, para lo cual resulta recomendable que se les fije por ley un plazo de duración, exigiendo una evaluación previa a su posible renovación. Se debiera establecer un sistema de evaluación de franquicias, análogo al que existe hoy en Dipres, para la evaluación de programas de gasto.

(iii) El IVA debe preservarse como nuestro principal impuesto, con una tasa única, y debe continuar extendiéndose a todas las actividades, eliminando las excepciones que todavía persisten

En particular, debería extenderse el IVA a las ventas de todos los bienes raíces nuevos, a base de la tasa general que grava a otros bienes, 
terminando así de asimilarlo al régimen general, en línea con las modificaciones tributarias de los últimos veinte años. Actualmente, las viviendas de valor inferior a las UF 4.500 cuentan con un crédito especial equivalente a aplicar una tasa reducida de IVA de 6,65\%. En ese sentido, parece conveniente focalizar este beneficio en aquellas viviendas que la política habitacional del Estado pretende subsidiar, que actualmente son viviendas de hasta UF 2.000. Para este propósito, el subsidio habitacional vigente debería elevarse para compensar el encarecimiento de la vivienda resultante de este cambio en el IVA. Para evitar la posible elusión del impuesto, es conveniente también gravar no solo la primera venta de los bienes raíces a un intermediario, sino también las siguientes que realicen intermediarios que no serán los usuarios finales del bien raíz. De acuerdo a las estimaciones presentadas en el trabajo de Jorratt, el efecto conjunto de estas dos medidas recaudaría en términos brutos del orden de US\$ 700 millones. Sin embargo, si a dicha cifra le restamos el costo de elevar los subsidios habitacionales para contrarrestar el alza en el valor de las viviendas afectas a subsidio, vale decir hasta UF 2.000, entonces la mayor recaudación neta sería de alrededor de US\$ 560 millones anuales.

Asimismo, es recomendable eliminar la exención al transporte aéreo de pasajeros. Como este servicio es utilizado mayoritariamente por empresas, su efecto recaería en reducir distorsiones y tendría un costo en menor recaudación, estimada en cerca de US\$28 millones anuales, debido a que las compañías aéreas podrán recuperar el IVA por sus insumos y los montos a recuperar serán mayores que lo que se recaude de IVA por ventas a consumidores finales.

En el caso del resto de los servicios, en el trabajo de Jorratt se proponen algunas alternativas para mejorar la forma en que actualmente se integran al régimen general del IVA. El tratamiento tributario de los servicios es una materia que requiere actualizarse a la par con la creciente importancia de los servicios en la economía. Aquí se recomienda, en una etapa inicial, dar prioridad al tratamiento de las exportaciones de servicios empresariales en vista de la creciente importancia de estas exportaciones para el desarrollo del país. En particular, a fin de no perjudicar la exportación de servicios empresariales, se les debería dar el mismo trato que reciben las exportaciones de bienes, extendiendo la tasa cero a las exportaciones de servicios empresariales. El costo estimado de esta medida sería del orden de los US\$ 180 millones anuales. 
Se debe señalar eso sí, que dada la naturaleza de los servicios, su aplicación tiene riesgos mayores de evasión, por tanto, su implementación debe hacerse cuidando especialmente la mitigación de esos riesgos.

Los servicios financieros están actualmente exentos del IVA, tal como ocurre prácticamente en todos los países de la OCDE. Sin embargo, en nuestro país existe un impuesto muy similar, que es el llamado impuesto de timbres y estampillas. Resulta por tanto recomendable que mientras no sea factible avanzar en gravar los servicios financieros con el IVA, se mantenga este impuesto con una tasa equivalente a lo que representaría aplicar la tasa general del IVA. En el estudio de Yáñez (capítulo 3) se determinó que esa tasa equivale a un $0,0667 \%$ mensual con un máximo de $0,8 \%$ anual, levemente mayor que la actual tasa del $0,05 \%$ mensual con un nivel máximo anual de $0,6 \%$. Dado que este impuesto se aplica en sustitución del IVA, debiera tener un trato equivalente al IVA que grava a otros insumos y por lo tanto debiera ser crédito de los pagos por IVA ${ }^{10}$. Se estima que esto tendría un impacto neto de reducir la recaudación en cerca de US\$ 220 millones.

\section{(iv) Impuestos a externalidades negativas}

Entre los impuestos a las externalidades negativas es recomendable avanzar en el uso de impuestos verdes. En el sistema chileno, tal como en el resto del mundo, los principales impuestos verdes son los que gravan a los combustibles. En esto resulta necesario seguir usando el sistema tributario como mecanismo que desaliente la generación de externalidades negativas. En el estudio de Yáñez se estima que el impuesto actual al petróleo diésel es sustancialmente inferior al que correspondería aplicar en virtud de las externalidades negativas que produce en el medio ambiente. En el caso del diésel hay otro problema adicional que se requiere corregir. En la actualidad existen créditos especiales al IVA cuando el diésel se usa como insumo intermedio en la producción, con lo cual de hecho no existe impuesto a la externalidad en su uso como insumo intermedio. Esto es equivalente a subsidiar el uso del diésel en la producción. Al mismo tiempo, este aprovechamiento del crédito tributario estimula la organización y creación de empresas con el único propósito de aprovechar el beneficio tributario.

${ }^{10}$ Este tratamiento ya se permite para las empresas de menor tamaño y aquí se sugiere extenderlo a todos los contribuyentes de IVA. 
En la misma dirección, es recomendable avanzar en aplicar un impuesto corrector a los otros combustibles contaminantes usados como insumo intermedio en la producción (carbón, gas, leña, etc.).

Conviene tener en cuenta asimismo que la actual recaudación por concepto de impuestos a los combustibles no alcanza a financiar el costo para el Estado de mantener y financiar la infraestructura vial que no está afecta a cobro por su uso. Lo recomendable es que la infraestructura vial sea financiada por sus usuarios y mientras no exista un sistema tecnológicamente adecuado para hacer ese cobro, lo más recomendable es seguir utilizando el gravamen a los combustibles.

Comparado con los países de la OCDE, la tasa de impuesto a la gasolina en Chile es menos de la mitad de la tasa promedio de esos países, y en el caso del impuesto al diésel es menos de un quinto de la tasa media de esos países.

Con todos los antecedentes anteriores lo recomendable sería elevar gradualmente estos impuestos, particularmente el del petróleo diésel para igualarlo a la gasolina, y además eliminar el crédito en el IVA, que da origen al impuesto sobre el diesel de los vehículos de carga, y la exención del impuesto específico al petróleo diesel de uso no vehicular. Es importante la gradualidad para que los consumidores se ajusten al mayor costo que representa llegar a los niveles de impuesto que compensarían las externalidades asociadas al consumo de petróleo diésel y gasolina, y que se acercan a los gravámenes de los países de la OCDE. El aumento de recaudación por este concepto se estima en unos US\$ 1.500 millones anuales ${ }^{11}$.

En lo que respecta a los impuestos a los tabacos y al alcohol, se podría mejorar su aplicación, si como se recomienda en el trabajo de Yáñez, siguiendo las mejores prácticas en esta materia, se grava la cantidad consumida en vez de su valor. En el caso del tabaco debería gravarse el número de cigarrillos y en el caso del alcohol, la cantidad de gramos de alcohol puro contenido en cada bebida alcohólica, manteniendo la actual recaudación que se estima está a un nivel acorde con las externalidades producidas. El cambio en el diseño de estos impues-

${ }^{11}$ De este monto, US\$ 980 millones corresponden a lo que se recaudaría de igualar la tasa del impuesto específico del diésel con el de la gasolina en UTM 6 por metro cúbico. El resto se obtiene de eliminar el crédito en el IVA, que da origen al impuesto sobre el diésel en el transporte de carga, y la exención del impuesto específico al petróleo diésel de uso no vehicular. 
tos permite dirigir en forma más precisa el gravamen a la externalidad que se produce.

\section{(v) Impuesto a la renta de empresas y personas}

El sistema de impuestos a la renta de empresas y personas en Chile, aparte de estar totalmente indexado al IPC, está totalmente integrado. Estas disposiciones han sido propuestas en los proyectos de reforma de los países de la OCDE, sin embargo, en Chile ya están presentes, por lo tanto, es fundamental preservarlas.

En esos países la tendencia de las reformas ha sido ampliar la base tributaria y reducir las tasas para así disminuir las distorsiones que crean los impuestos. Con todo, la recaudación por este concepto como porcentaje del PIB es bastante menor en Chile que en los países de la OCDE. En promedio, para el período 2005-09, el último con datos comparables, en Chile se recaudó el $8 \%$ del PIB mientras en el promedio de la OCDE la recaudación fue del $12,2 \%$ del PIB.

En lo que se refiere al impuesto a la renta, hay varias materias que recomendamos revisar: en primer lugar, el régimen especial llamado renta presunta. Este régimen se creó con el propósito de reducir el costo del cumplimiento tributario y de la fiscalización de los contribuyentes cuando no existían las facilidades tecnológicas que hoy están disponibles para registrar y declarar los impuestos. Es necesario revisarlo a la luz de la realidad actual del país y de los sectores que son favorecidos por ese sistema. Resulta recomendable en este caso reemplazar los regímenes de renta presunta por el actual régimen 14 ter, que está destinado a gravar en forma simplificada a pequeños contribuyentes. En el estudio de Agostini se simuló este cambio sobre la base de una muestra representativa de contribuyentes. Lo primero que llama la atención es que de las 18.098 empresas ${ }^{12}$ que hoy se acogen al régimen de renta presunta, el $86,5 \%$ de las utilidades de estas empresas pertenecen a contribuyentes que están en el decil de más altos ingresos. Se simuló el reemplazo del régimen de renta presunta por el régimen 14 ter, elevando casi en tres veces el máximo de ventas requerido para acogerse a este régimen a UF 25 mil, que es la definición de CORFO para pequeñas empresas (actualmente el límite es

${ }^{12}$ Esto excluye a los taxis colectivos y particulares. 
de 5 mil UTM, lo que equivale a menos de UF 8.800). De acuerdo a las simulaciones realizadas por Agostini, el resultado es que todos los contribuyentes que actualmente están exentos permanecen en esa situación y que poco menos de 1.600 contribuyentes que hoy se acogen a renta presunta, teniendo ingresos efectivos muy superiores, verían aumentar el pago de sus impuestos, generando una recaudación adicional de US\$ 60 millones anuales y corrigiendo una situación de gran inequidad horizontal y que al mismo tiempo reduce la progresividad del impuesto a la renta.

En segundo lugar, es recomendable reemplazar los otros sistemas especiales como el 14 bis y el 14 quáter por el 14 ter, elevando el límite de ventas aplicable en los términos descritos más arriba ${ }^{13}$. Este último permite una mejor fiscalización de los contribuyentes afectos a regímenes especiales. La mayor recaudación al eliminar estas dos medidas sería del orden de los US\$ 47 millones anuales.

En tercer lugar, deben revisarse las franquicias que se han creado con el propósito de promover el mercado de capitales. La única excepción deberían ser aquellas que promueven el ahorro previsional y/o permiten a los contribuyentes ahorrar para el retiro, vale decir, extender el período en el cual se mide el ingreso que es gravado. Deben revisarse y eliminarse el resto de las franquicias. En particular, es necesario revisar el trato diferenciado de distintas formas de ganancias de capital. En esta área se debe avanzar en ir acercando gradualmente su tratamiento tributario al que tienen las otras fuentes de ingreso. Se debiera, eso sí, descontar la tasa libre de riesgo del retorno bruto de la inversión, porque esa fracción es un insumo necesario para generar mayores ingresos en el futuro.

Otra área que es indispensable reformar es el tratamiento de los ingresos de los asalariados. Para ellos el período tributario al cual se aplica el impuesto es un mes. Nuestro sistema actualmente no permite que los asalariados puedan reliquidar el impuesto retenido en el año

${ }^{13}$ Unificar estos regímenes especiales contribuye a la equidad horizontal y a la eficiencia. El 14 ter es más recomendable que los otros regímenes, ya que al establecer la retención del impuesto de primera categoría, facilita su fiscalización. Asimismo su operatoria es más simple. Como la base imponible está determinada por ingresos menos gastos de las empresas, equivale a estimular la inversión en activos fijos, ya que se les otorga depreciación instantánea a la compra de activos. 
tributario correspondiente. Esto representa una inequidad que además afecta mayoritariamente a trabajadores de bajos ingresos. Como muestran las estimaciones de Agostini, más del 65\% del costo de esta situación recae sobre trabajadores del quintil de menores ingresos. La recomendación en esta área es introducir la reliquidación de este impuesto para restablecer la equidad horizontal en favor de contribuyentes de ingresos más bajos. Esta medida tiene un costo de menor recaudación estimada en unos US\$ 24 millones anuales.

En cuanto a la forma en que se gravan los ingresos obtenidos por las utilidades de las empresas, el sistema chileno desde 1984 grava las utilidades al momento en que son distribuidas. El impuesto a las sociedades es uno de retención, que se acredita en el pago del impuesto al global complementario de las personas al momento en que esas utilidades son retiradas y por tanto en ese momento se pagan los impuestos personales por dichas utilidades. Este mecanismo constituye un incentivo a retener utilidades para todos los contribuyentes, cuya tasa marginal de impuestos personales es superior a la tasa del impuesto que grava a las empresas (situación que ocurre actualmente para contribuyentes con rentas anuales superiores a $\$ 33$ millones). En los hechos, para el conjunto de las sociedades que declararon impuestos, los retiros han sido algo superiores al $31 \%$ de las utilidades tributarias como promedio en los últimos diez años. Es por tanto un estímulo al ahorro en las empresas o sociedades y una fuente de financiamiento para la inversión vía reinversión de utilidades. Aunque no hay estimaciones precisas, sin duda esto ha contribuido a que en las últimas décadas el ahorro de empresas represente una fracción significativa del ahorro nacional.

Este esquema establece un beneficio a favor de los contribuyentes que obtienen rentas del capital o de sus sociedades, en comparación con quienes obtienen ingresos por su trabajo (vía sueldos y honorarios), los cuales no pueden ahorrar de esa manera, postergando el pago de sus impuestos. Esto también genera un incentivo a formar sociedades con el único propósito de beneficiarse de este mecanismo de tributación al momento del retiro. Asimismo, este sistema es más fácil de eludir, ya que las utilidades podrían tributar muchos años después de haber sido generadas. El incentivo a la evasión y elusión crece debido a la diferencia entre la tasa marginal del impuesto a las personas comparada al de las empresas. Esta diferencia es actualmente superior a 20 puntos porcentuales ( $40 \%$ la tasa marginal máxima de las personas y $17 \%$ en régimen 
de la tasa del impuesto de primera categoría). En un sistema en que se gravan las utilidades devengadas, las tasas de impuesto a las personas pueden ser más bajas, reduciendo las diferencias entre el tratamiento a los ingresos del trabajo y del capital, y desincentivando los incentivos a la formación de sociedades y evasión o elusión tributaria.

El trabajo de Agostini examina en detalle alternativas de tributación a las utilidades de las empresas. Para estudiar este tema, como parte de este proyecto se realizaron simulaciones inéditas en nuestro país. A través de un meticuloso estudio, se logró elaborar una muestra representativa de contribuyentes asociándolos con sus respectivas sociedades en las cuales participan directa o indirectamente, asignando así todas las rentas de la cadena de sociedades al contribuyente final, que es una persona natural. Entre ellas, y con el fin de reducir las diferencias entre la tasa que grava a empresas y personas, se simuló lo que sucedería si se gravaran las utilidades devengadas (en vez de los retiros) y se redujeran las tasas del impuesto global complementario a cuatro tramos con una tasa marginal máxima de 30\%. Para mantener el estímulo a la inversión en capital fijo, se consideró la aplicación de depreciación acelerada al máximo, es decir, depreciación instantánea. De acuerdo a esta simulación, con una tasa a las utilidades devengadas del $25 \%$, la recaudación anual se eleva en US\$ 1.077 millones. Además se produce una fuerte redistribución entre contribuyentes, ya que aproximadamente 78.900 contribuyentes, cuyos ingresos provienen principalmente del capital, ven elevados sus impuestos personales, y 297 mil, que pagan principalmente por su trabajo, los ven disminuir.

Alternativamente, manteniendo el sistema actual en que se paga sobre la base de retiros de utilidades - para no arriesgar un debilitamiento del estímulo al ahorro-, lograr el objetivo de mayor equidad horizontal y eficiencia se requiere avanzar en reducir exenciones y regímenes especiales por sus efectos en la equidad y la progresividad. En esta dirección, el reemplazo de los regímenes especiales de renta presunta, del 14 bis y del 14 quáter por el 14 ter, ya discutido más arriba, es una medida recomendable. En esa misma línea, también es recomendable generalizar el sistema que grava a las empresas, asimilando todos los casos al régimen tributario que se aplica a las sociedades anónimas, incluyendo los Fondos de Inversión Privados (FIP). No es conveniente que el régimen tributario de la renta a las empresas difiera dependiendo de si se trata de una sociedad anónima o no, con la única excepción de 
quienes se acogen al 14 ter. Para asimilar el trato de sociedades de personas al de las sociedades anónimas se debe revisar el tratamiento de los retiros de utilidades financieras que superan las utilidades tributarias en las sociedades de personas, así como el tratamiento de los gastos rechazados. La mantención del sistema que grava los retiros hace también recomendable revisar el tratamiento de las pérdidas tributarias y el plazo y situaciones en que se pueden acreditar contra otros impuestos.

Asimismo, se simuló el efecto de mantener la tasa del 20\%, que ha gravado a las empresas de manera transitoria, bajando la tasa marginal máxima que grava a las personas al $37 \%$ con el propósito de disminuir la brecha de tasas y así reducir el estímulo a la elusión ya mencionado. Tal modificación genera una recaudación neta adicional de US\$ 980 millones. En la medida que se va ampliando la base de impuestos a través de la eliminación de exenciones y franquicias que la erosionan, se podría seguir reduciendo la tasa marginal máxima y, con ello, la brecha existente con la tasa de primera categoría.

La información disponible no permitió estimar el efecto de todos estos cambios del impuesto a la renta y a los ingresos que aquí se sugieren. Se simuló eso sí la eliminación de regímenes especiales y exenciones ${ }^{14}$. Este conjunto de modificaciones genera, por concepto de impuesto a la renta, una mayor recaudación anual en régimen de unos US\$ 1.460 millones y a la vez mejora la equidad horizontal, la progresividad y la eficiencia del sistema tributario.

\section{(vi) Suficiencia de la recaudación}

Como se destacó más arriba, la suficiencia de la recaudación para financiar el gasto fiscal en una perspectiva de mediano plazo es un principio esencial que debe cumplir un sistema tributario que preserve una sólida solvencia de las cuentas fiscales. Esta ha sido una característica distintiva de nuestro sistema tributario por más de veinte años, que se

${ }^{14}$ Aparte de las correcciones ya mencionadas más arriba, se consideró la eliminación del crédito por compras de activo fijo que, al sumarse a la depreciación acelerada, en ciertos casos permite una depreciación tributaria superior a la inversión. Asimismo, se homologó el tratamiento del leasing con el que se recibe la compra de activos financiada con crédito y se consideró la homologación del tratamiento tributario que perciben las sociedades de personas con aquel percibido por las sociedades anónimas, en lo que se refiere a retiros en exceso y gastos rechazados. 
consolidó con la regla de balance fiscal ajustado por el ciclo y que debe preservarse. No ha sido el propósito de este estudio evaluar la suficiencia de la recaudación que genera el actual sistema tributario, sin embargo, algunas observaciones en ese sentido son necesarias al momento de hacer recomendaciones sobre nuestra estructura tributaria.

La carga tributaria chilena, incluyendo todos los impuestos, alcanzó el 2011 un 21\% del PIB, similar al promedio del quinquenio 2006-10 (abarcando todos los impuestos de Codelco y los impuestos de beneficio municipal). Así, el nivel de la carga tributaria chilena es superior al promedio de América Latina (13,5\% del PIB) e inferior al promedio de la OCDE $(25,7 \%)$. Para una mejor comparación de las obligaciones que enfrentan los contribuyentes chilenos es importante incluir los pagos al sistema de seguridad que, en el caso chileno, está en su gran mayoría al margen del sistema tributario y del presupuesto fiscal, aunque, desde el punto de vista de las personas y empresas, constituyen aportes obligatorios con cargo a sus ingresos (ni los beneficios previsionales ni las cotizaciones obligatorias para obtenerlos son parte de los ingresos y gasto fiscal). Si se agregan las cotizaciones obligatorias a la seguridad social a los impuestos, la carga en Chile es de $28 \%$ del PIB, comparado al $19 \%$ en América Latina y al $34 \%$ en la OCDE. Nuestro país se encuentra en una situación comparable a la de EE.UU. y superior a los países de Asia, pero por debajo de los países de la Unión Europea. Sin embargo, si se ajusta por el nivel de ingreso per cápita las diferencias con los países de la OCDE se reducen. Desde el punto de vista de la competitividad internacional, el nivel de la carga tributaria actual no es bajo, por tanto hay un espacio, aunque limitado, para elevar la carga.

El tamaño de la recaudación tributaria que requiere el país es una decisión que debe tomar en cuenta el nivel necesario de gasto público para proveer los bienes públicos, tomando debida cuenta de la eficiencia del gasto público y los efectos de los impuestos en el crecimiento y el bienestar. El propósito de este trabajo ha sido el de revisar opciones de política para mejorar la eficiencia y la equidad del sistema tributario chileno. En particular, el trabajo no busca determinar cuál es la recaudación tributaria que el país requiere para los próximos años. Sin embargo, el estudio aquí realizado es útil para señalar las opciones disponibles para generar más ingresos fiscales mediante políticas encaminadas a cerrar vacíos que no solo reducen los ingresos públicos, sino que también hacen menos equitativo el sistema tributario. 
El conjunto de recomendaciones que aquí se han priorizado para mejorar la equidad horizontal y vertical, la progresividad y la eficiencia del sistema tributario, podrían generar una mayor recaudación neta del orden de US\$ 3.100 millones, los cuales llegarían a US\$ 5 mil millones si se agregasen los US\$ 1.900 millones de mayor recaudación que se podrían obtener por hacer retroceder la evasión.

Una evaluación de la suficiencia de la recaudación, que no fue el propósito de este proyecto, debiera considerar los elementos que a continuación detallamos.

Acerca de las necesidades fiscales de mediano plazo, las estimaciones de la situación fiscal sobre la base de la legislación vigente a septiembre pasado, presentadas con motivo de la ley de presupuestos del 2012, mostraban una holgura de recursos para el período 2013-15 muy reducida, a pesar de considerar ingresos fiscales favorecidos por los altos precios del cobre. De hecho, para el trienio 2013-15, la proyección realizada al presentar el proyecto de presupuestos estima que no existen holguras, sino un déficit estructural anual promedio del 1,0\% del PIB. A lo anterior cabría agregar las nuevas iniciativas de gasto que se han enviado al Congreso Nacional o se han comprometido con posterioridad a septiembre pasado. Entre ellas, las principales en términos de mayores gastos son las iniciativas para mejorar la educación y el financiamiento del Transantiago.

En cuanto a la sustentabilidad de la recaudación tributaria, es imprescindible destacar que el actual período registra uno de los mayores precios históricos del cobre. La recaudación fiscal por concepto de la minería del cobre el año pasado llegó a 3,5\% del PIB y para este año se proyecta una cifra similar. Se trata de recaudaciones que el país no ha conocido en el pasado y que dependen de la mantención del ciclo de precios altos que se está experimentando. Esto obliga a la prudencia en su uso, además de la conveniencia de ahorrar parte de esos ingresos por tratarse de entradas derivadas de recursos no renovables. La regla fiscal chilena permite lograr llevar a la práctica esta prudencia al gastar de acuerdo a los ingresos ajustados por el ciclo. La misma meta fiscal puede redefinirse para alcanzar un valor suficientemente positivo y así acumular recursos para el futuro, previendo el agotamiento de los recursos no renovables y, al mismo tiempo, protegiendo al resto de los sectores transables de la pérdida de competitividad por efecto tipo enfermedad holandesa. 
Por último, debe considerarse la realidad internacional, tanto porque el sistema tributario debe mantener la competitividad de nuestra economía como para comparar nuestra situación con la de los países actualmente desarrollados cuando estaban en nuestra etapa de desarrollo.

En síntesis, desde el punto de vista de la suficiencia de los recursos tributarios, el país requiere de una recaudación superior a la que se obtiene con la actual estructura tributaria. En este documento se han propuesto distintas alternativas para perfeccionar el sistema tributario, las que resultan también en un aumento de la recaudación tributaria ajustada por el ciclo. Se pueden eliminar franquicias, regímenes especiales y exenciones que, junto con contribuir a una mayor equidad horizontal, elevan la recaudación tributaria. Se puede acometer también una serie de iniciativas para elevar la recaudación haciendo retroceder la evasión a niveles que el país ya logró en años recientes, acelerando la tendencia de los últimos dos años. Por supuesto que también es indispensable evaluar la eficiencia del gasto público en términos de la efectividad en el logro de los objetivos que se persiguen con este.

\section{REFERENCIAS BIBLIOGRÁFICAS}

Agostini, Claudio A. (2012). "Una reforma eficiente y equitativa del impuesto al ingreso en Chile". En J. P. Arellano y V. Corbo, Tributación para el desarrollo: Estudios para la reforma del sistema chileno. Santiago: CEP-Cieplan.

Brys, Bert, Stephen Matthews y Jeffrey Owens (2011). "Tax Reform Trends in OECD Countries". OECD Taxation Working Papers, No. 1. OCDE Publishing.

Jorratt, Michel (2012). "Gastos tributarios y evasión tributaria en Chile: Evaluación y propuestas”. En J. P. Arellano y V. Corbo, Tributación para el desarrollo: Estudios para la reforma del sistema chileno. Santiago: CEP-Cieplan.

Meade, James E. (1978). The Structure and Reform of Direct Taxation. Report of a Committee Chaired by Professor James E. Meade. London: George Allen \& Unwin.

Mirrlees, James, Stuart Adam, Tim Besley, Richard Blundell, Stephen Bond, Robert Chote, Malcolm Gammie, Paul Johnson, Gareth Myles y James Poterba (eds.) (2011). Tax by Design: The Mirrlees Review. Oxford: Oxford University Press for Institute for Fiscal Studies.

Report of the President's Advisory Panel on Federal Tax Reform (2005). "Simple, Fair, and Pro-Growth: Proposals to Fix America's Tax System". Disponible en http://www.taxpolicycenter.org/taxtopics/ upload/tax-panel-2.pdf. 
Yáñez, José (2012). “Impuestos indirectos en Chile: Análisis y propuestas de reformas". En J. P. Arellano y V. Corbo, Tributación para el desarrollo: Estudios para la reforma del sistema chileno. Santiago: CEP-Cieplan. 